\title{
Construction of Formative Assessment System of College English Writing Based on the Cultivation of Critical Thinking Ability
}

\author{
Huang $\mathrm{He}^{1, a}, \mathrm{Xu} \mathrm{Lei}^{2, \mathrm{~b}}$ \\ 1,2 Jiangxi Institute of Economic Administrators, Nanchang, Jiangxi, 330088 China \\ a85606299@qq.com, b694934089 @qq.com
}

Keywords: Critical thinking; external factors; multi-dimensional cultivation mode

\begin{abstract}
As the important cultivation target of the higher education, cultivation of critical thinking is a weak process in foreign language teaching. On the basis of attempting relevant studies and investigation results, the multi-dimensional cultivation mode with the orientation of emotional cultivation, basis of subject contents, support of independent study, and safeguard of formative evaluation, the study devoted itself to improving college students' critical thinking in foreign languages.
\end{abstract}

\section{Introduction}

The critical thinking can analyze, identify, question, reflect and evaluate things. It is considered as an important index to embody students' independent reflection and it is one of core values in the college education.

\section{The Theoretical Model of Critical Thinking Skill Hierarchy}

The first hierarchy in the theoretical model of critical thinking is the meta-critical thinking. It is a skill to plan, inspect, adjust and evaluate speculation. The second hierarchy includes critical thinking, cognitive skills and emotional traits and accepts the management and monitoring of meta-critical thinking (see Table 1).

Tab.1 Theoretical Model of the Critical Thinking Skill Hierarchy (see Wen Qiufang, et al., 2009:42)

\begin{tabular}{|c|c|c|}
\hline \multicolumn{3}{|c|}{ Meta-critical Thinking (Self-regulation Ability) - the First Hierarchy } \\
\hline \multicolumn{3}{|c|}{ Critical thinking-the Second Hierarchy } \\
\hline \multicolumn{2}{|r|}{ Cognition } & \multirow{2}{*}{ Emotions } \\
\hline Skills & Standards & \\
\hline $\begin{array}{l}\text { Analysis(Classification, } \\
\text { identification, comparison, } \\
\text { clarification, distinction } \\
\text { and elaboration) } \\
\text { Reasoning(question, } \\
\text { assumption, deduction, } \\
\text { elaboration and } \\
\text { demonstration) } \\
\text { Evaluation(Judgment } \\
\text { preset, assumption, thesis, } \\
\text { argument and conclusion) }\end{array}$ & $\begin{array}{l}\text { Explicitness(distinction and } \\
\text { accuracy) } \\
\text { Dependency(Keep to the point, } \\
\text { proper details and omissions, } \\
\text { and make a distinction) } \\
\text { Logicality(Clear orderliness } \\
\text { and well-founded reasoning) } \\
\text { Profundity(Breadth and width) } \\
\text { Flexibility(Rapid variation and } \\
\text { flexibly and alternatively use } \\
\text { different critical thinking }\end{array}$ & $\begin{array}{l}\text { Curiousness(Suspicious, } \\
\text { inquisitive and studious) } \\
\text { Openness(Tolerant, respect } \\
\text { different opinions, and take delight } \\
\text { in correcting improper opinions) } \\
\text { Confidence(Believe in the own } \\
\text { judging ability and dare to } \\
\text { challenge authority) } \\
\text { Uprightness(Seek the truth and } \\
\text { advocate justice ) } \\
\text { Persistence(Determined, persistent } \\
\text { and never give up) }\end{array}$ \\
\hline
\end{tabular}




\section{The Construction of the Formative Evaluation System Based on the Critical Thinking Skill Cultivation}

The author summarized four key strategies of the formative evaluation, including define learning purposes and successful standards; develop the effective classroom discussion and learning tasks, and always evaluate teaching based on the four key strategies.

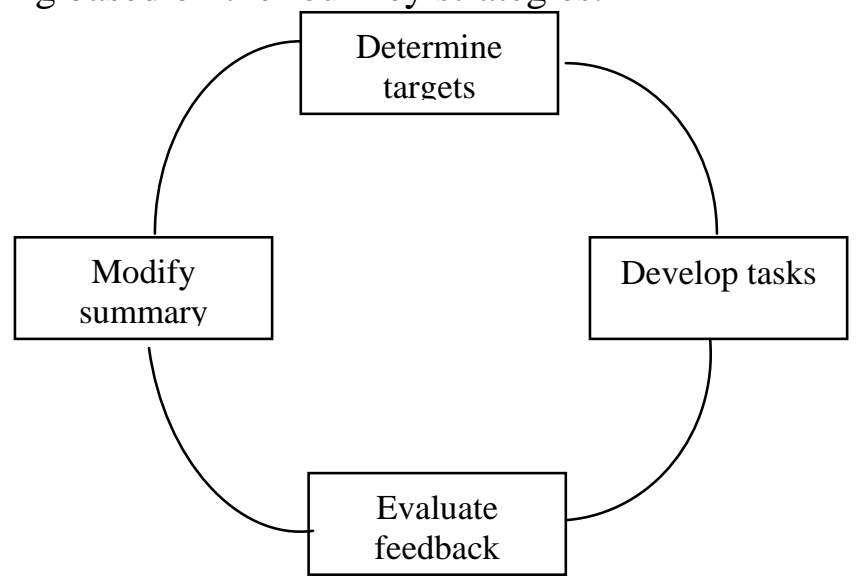

Fig.1 The Structure of the Formative Evaluation System

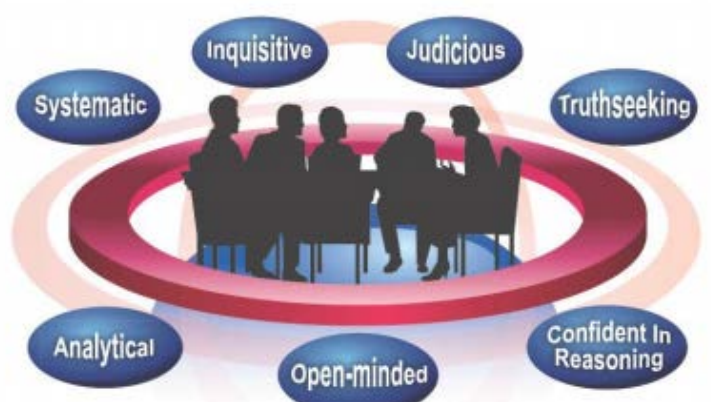

Fig.2 Critical Thinking Habits of Mind from APA Report: Expert Consensus Statement on Critical Thinking

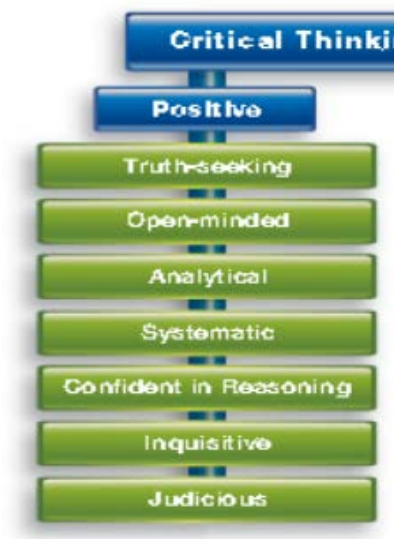

Fig. 3Critical Thinking Habit of Mind from Think Critically

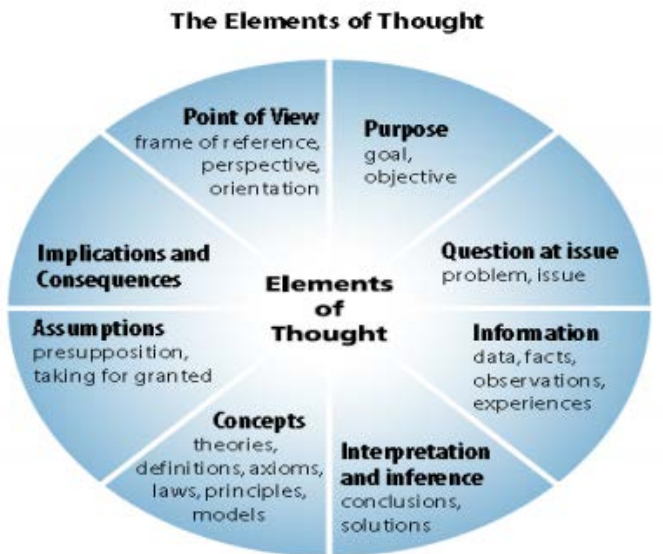

Fig.4 The Elements of

Reasoning in Paul's Model

Common formulation of teachers and students and target determination are primary process for the formative evaluations system. The target is the power and direction for students' study. When teachers and students reach a consensus in the target concept and evaluation standards, students can fully understand and absorb teachers and other people's feedback information and conduct the objective evaluation and reflection on the task completion situations. At the beginning of term, teachers should help students to understand composition and standards of the critical thinking, guide students to discuss and formulate evaluation standards of writings. For relatively abstractive evaluation standards, teachers can provide the model essay and conduct the deep analysis and help 
students to comprehend and master. In order to record and reflect on the learning process, students will construct a file cover at the beginning of the term, formulate a learning plan in line with learning targets and evaluation standards, and place it in the file cover, so that they can supervise their learning process at anytime. In addition, the file cover also includes students' first draft, revised manuscript, final draft, self-evaluation, mutual evaluation and teachers' feedback. Also, it is necessary to comprehend and reflect on teachers' teaching and personal learning situation. The previous score proportion on composition evaluation criterion can't stand out importance of students' critical thinking. This is also an important factor to restrain students' critical thinking development. In the aspect of evaluating students' composition critical thinking, the author designed the critical thinking of argumentative writings(Table 2).

Tab.2 The Critical Thinking Score of Argumentative Writings

\begin{tabular}{|c|l|}
\hline \multirow{4}{*}{ Ideological contents(40\%) } & Profound thought and abundant contents(10\%) \\
\cline { 2 - 2 } & Definite and suitable argument and thesis \\
\cline { 2 - 2 } & Sufficient demonstration and representative argument(10\%) \\
\cline { 2 - 2 } & No prejudice or discriminatory language(10\%) \\
\hline \multirow{4}{*}{ Layout (30\%) } & Complete and reasonable structure(10\%) \\
\cline { 2 - 2 } & $\begin{array}{l}\text { Natural and reasonable transition between sentences and } \\
\text { paragraphs(10\%) }\end{array}$ \\
\cline { 2 - 2 } & Clear and reasonable logicality(10\%) \\
\hline \multirow{3}{*}{ Proper wording(30\%) } & Proper language style(10\%) \\
\cline { 2 - 2 } & Sufficient consideration on readers' demands(10\%) \\
\cline { 2 - 2 } & Accurate, clear and specific language(10\%) \\
\hline
\end{tabular}

\section{The Research Design of the Formative Evaluation System Based on the Critical Thinking}

The study applied the method combining the investigation with interview.

A. Research Questions

This study tried to answer the following two questions: 1 . Based on the definition of the critical thinking, the "Delphi” project group investigated how college students in foreign languages evaluate their critical thinking? 2) In terms of college students in foreign languages, which external factors in the teaching process affect the development of critical thinking?

B. Research Objects

These research objects included 197 junior students in Non-English major of 4 college students in Jiangxi Province. According to their performance in CET-4, students' English competence was graded as excellent, good, qualified and unqualified. Before accepting the investigation, they had the clear cognition on the competent capacity of the critical thinking. After finishing the investigation, the author interviewed teachers and English education experts in relevant colleges and collected relevant data.

C. Research Tools

The questionnaire included Part A and Part B. Part A included Part B of Rao's original table, but it was slightly changed. Yes or No choice questions in the original table were changed into Likert five-level scale form. 1 was very strong, while 5 was very weak. Based on the definition on the critical thinking, the "Delphi” project group investigated foreign language colleges' evaluation on various skills of the critical thinking in 1, 2, 3, 4,5, 6,7, and 8. "1 very strong" had 5 scores, while " 5 very weak" had 1 score. In this way, after adding all scores, the higher scores would be higher, showing that the critical thinking would be stronger. Part B was the same with the Part C in Rao's original table (2002), it required students to select external factors affecting their critical thinking development ${ }^{1}$. The questionnaire regarded the school as a unit to fill in grade, gender, major and English competence.

The second research tool was interview. A total of 15 English teachers and English education experts attended it. The author recorded the interview contents and let interview teachers and experts to confirm it after transferring the recording into characters. 


\section{Data Collection and Analysis}

This investigation was conducted in March 2017. A total of 216 questionnaires were granted. 204 of them were recycled. 7 invalid questionnaires were excluded. There were 197 actual invalid questionnaires. The data collection and statistics were completed in the end of April. SPSS13.0 was used to complete data statistics and analysis. The statistical method was One Way Analysis of Variance. In other words, the relation between a nominal level variable and other nominal level variable was analyzed. The sample mean was compared.

E. Investigation Results

How college students in foreign languages can evaluate their critical thinking.

Tab.3 Statistical Analysis of College Students in Foreign Languages in Their Critical Thinking Evaluation

\begin{tabular}{|c|c|c|c|}
\hline Mean & Standard value & Minimum & Maximum \\
\hline 23.84 & 5.26 & 18 & 34 \\
\hline
\end{tabular}

Shown in Table 3, the author calculated the mean, standard value, minimum and maximum on their critical thinking evaluation. From the perspective of statistics, above 32 scores, students thought they had the strong critical thinking. With $24<$ scores $<32$, students held the neutral attitude. Below 24 scores, students thought their critical thinking was weak as a whole. It could be observed from Table 1 that students didn't have the higher evaluation on their critical thinking.

The contrastive analysis of students with different English competence on their critical thinking was shown as follows

Tab.4 Contrastive Analysis of Different English Levels on Their Critical Thinking Evaluation

\begin{tabular}{|c|c|c|c|c|c|c|}
\hline $\begin{array}{c}\text { English } \\
\text { level }\end{array}$ & Mean & $\begin{array}{c}\text { Standard } \\
\text { value }\end{array}$ & Minimum & Maximum & $\mathrm{F}$ & $\mathrm{P}$ \\
\hline Excellent & 75.38 & 7.13 & 59 & 99 & & \\
\cline { 1 - 5 } Good & 74.67 & 7.19 & 58 & 100 & \multirow{2}{*}{3.77} & 0.17 \\
\hline Qualified & 74.11 & 7.23 & 55 & 102 & & \\
\hline Unqualified & 73.92 & 7.31 & 57 & 98 & & \\
\hline
\end{tabular}

The investigator thought that seven external factors affecting their critical thinking(shown in Table 5)

Tab.5 External Factors Affecting College Students’ Critical Thinking Development in Foreign Languages

\begin{tabular}{|c|c|c|c|}
\hline Ranking & Factors & Times & Percents \\
\hline 1 & Evaluation standards & 141 & $71.6 \%$ \\
\hline 2 & Test system & 134 & $68.0 \%$ \\
\hline 3 & Teaching mode & 132 & $67.0 \%$ \\
\hline 4 & Course setting & 127 & $64.5 \%$ \\
\hline 5 & Teaching materials & 110 & $55.8 \%$ \\
\hline 6 & Learning mode & 107 & $54.3 \%$ \\
\hline 8 & Teachers & 104 & $52.8 \%$ \\
\hline Ters & 6 & $63.0 \%$ \\
\hline
\end{tabular}

According to the investigation results, we interviewed Non-English major teachers and English education experts on how to affect college students' critical thinking development in foreign languages by using these seven factors:

1) In terms of the foreign language competence, evaluation standard interviewer mentioned that the traditional evaluation system only rested on the fluency of students' language expression, but neglected the complicity and accuracy of language expression.

2) In terms of Chinese foreign language course study, the test system interviewer mentioned that the examination tendency was obvious. In language proficiency test of various types in China, listening, reading, writing and translation had the overwhelming advantages. 
3) The teaching mode interviewer showed that the foreign language teachers might not value critical thinking, but focused on the language point explanation and language skill operation in the teaching emphasis. The extreme examples included repetition as the book and cramming education.

4) The course setting interview mentioned that specialized course for Non-English major had fewer hours and students' language proficiency was limited, thus the exercise space of critical thinking was also limited. For many years, the course setting of Non-English major and teaching practice in China adhere to the guiding thought of heavy input and light output and focus on accepting the skill exercise, but it is short of analysis on students' needs and neglects cultivation of students' thinking ability. In addition, there are more language skills courses in the course setting, but there are fewer knowledge courses. This is not good for the students' critical thinking development.

5) The teaching material interviewer indicated that the English starting point of freshman year in the Non-English major at most is the high-grade in primary schools of the native speakers. The compilation of teaching materials in the Non-English major breaks away from the cognitive level of Non-English major students. As a result, the teaching materials are short of the proper challenges for students' critical thinking. Some interviewers also mentioned that the topic involved by the teaching materials is generally related to daily life. Even if the complicated topic may not have the higher abstractive degree, this is not good for students' critical thinking development.

6) The learning mode interviewer indicated that Non-English major students give priority to imitate, memorize and restate the learning process. So many exercises obviously are not the best tasks for exercise analysis, reasoning and evaluation skills.

7) Some interviewer mentioned that many teachers are pressed by teaching tasks and pressure, so they are unwilling to use personal life experience and aesthetic experience to explain textbooks creatively. Some teachers infuse thoughts to students to maintain the absolute authority of teachers, but they are short of equal exchange between teachers and students. The questions and opinions proposed by students can't be sufficiently valued by students. In addition, teachers are short of subjective initiative. They rigidly adhere to textbook contents. In order to yield to students' difficulty of the lower language proficiency, learning tasks designed by teachers may not have too high requirements for the thinking level.

\section{Conclusions}

The critical thinking cultivation is an urgent problem in English educational circles. College English writing class is an important platform to cultivate students' critical thinking and has the important significance on improving students' integrated quality. By regarding the critical thinking cultivation as the target and considering the formative evaluation as the theoretical basis, the author discussed the confirmative target, task development, evaluation feedback and summary modification as four processes to construct the dynamic evaluation system, which indicates that students formulate the learning target and judge themselves and other people's works, and reflect on the subjectivity on themselves. In the process of self-analysis, self-supervision, reflection and adjustment, students' critical thinking is gradually enhanced. At the same time, teachers observe, summarize and reflect on each teaching process, provide high-quality feedback for students, and promote in-depth implement of critical thinking cultivation.

\section{Acknowledgements}

Period results of the fund project: "Study on College English Writing Teaching and the Cultivation of Students’ Critical Thinking.” 2015 Jiangxi Social Science program, "special project of foreign language teaching research in Jiangxi universities" (Project Code: 15WX327) 


\section{References:}

[1] Liu Xiaomin, the Discussion on the Construction of College English Teaching Critical Thinking Cultivation Mode[J], Foreign Language Circles, 2013, 05: 59-66;

[2] Zhang Shasha, the Study on the College English Reading and Writing Teaching Mode under the Perspective of Critical Thinking[J], Agricultural Staff, 2017, 10: 160;

[3] Lu Rong, the College English Course Teaching Reform Study under the Critical Thinking Field[J], Journal of Heilongjiang College of Education, 2017,03: 130-132;

[4] Tian Yuan, the Critical Thinking Cultivation and Application in English Teaching[J], Science Vision, 2017, 14: 84+56;

[5] Pan Linlin and Song Yi, the Cultivation of Cooperative Learning and Critical Thinking[J], the Foreign Language and Foreign Language Teaching, 2016, 02:97-105+147

[6] Wen Qiufang, A study on the thinking ability of Chinese foreign language students[M], Foreign Language Teaching and Research Press, 2012 